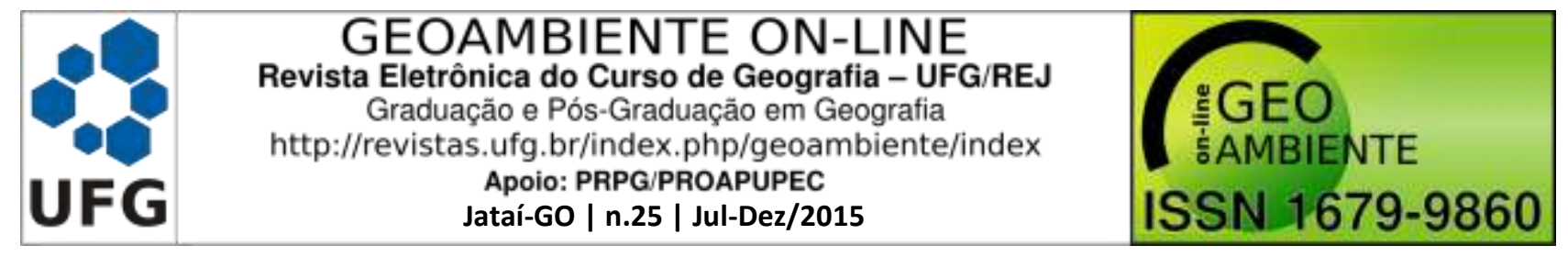

\title{
GEOGRAFIA E EDUCAÇÃO AMBIENTAL: PERCEPÇÃO DOS PROFESSORES SOBRE O USO DA GEOGRAFIA COMO FERRAMENTA PARA A EDUCAÇÃO AMBIENTAL EM BIRIGUI-SP
} Rafael Marques dos Santos ${ }^{1}$, Ana Gabriela Bueno Melo de Carvalho² (1 - Universidade Estadual de Maringá, Mestrando em Geografia, Docente Faculdade-Birigui, geografia.rafael@gmail.com, 2 - Faculdade Birigui, Docente, decarvalho.ag@gmail.com)

Resumo: A disciplina de Geografia é abordada por diversas vezes no PCN (Parâmetros Curriculares Nacionais) como fundamental para educação ambiental devido seus conceitos e abordagem diretamente ligados ao meio ambiente. Neste contexto, este artigo procurou levantar a percepção dos professores de Geografia a respeito da aplicabilidade dos conceitos de Geografia nas aulas de educação ambiental através de um questionário respondido por 20 professores selecionados aleatoriamente e de maneira voluntária nas escolas estaduais da cidade de Birigui-SP. Os dados revelaram que apesar do trabalho de educação ambiental realizado por $100 \%$ dos entrevistados, alguns conceitos fundamentais da Geografia ainda precisam ser trabalhados com os professores da rede estadual.

Palavras-Chave: Educação Ambiental; Ensino da Geografia; Percepção.

\section{GEOGRAPHY AND ENVIRONMENTAL EDUCATION: PERCEPTIONS OF}

\section{TEACHERS ON THE GEOGRAPHY OF USE AS A TOOL FOR ENVIRONMENTAL EDUCATION IN BIRIGUI-SP}

Abstract: The discipline of geography is addressed several times in the PCN (National Curriculum Parameters) as central to environmental education because its concepts and approach directly linked to the environment. In this context, this article aims to raise the awareness of Geography teachers regarding the applicability of the concepts of geography in environmental education classes through a questionnaire answered by 20 teachers selected at random and voluntarily basis in the public schools of the city of Birigui-SP. The data revealed that despite the environmental education work done by $100 \%$ of respondents, some fundamental concepts of geography still need to be worked with the teachers of the state. 


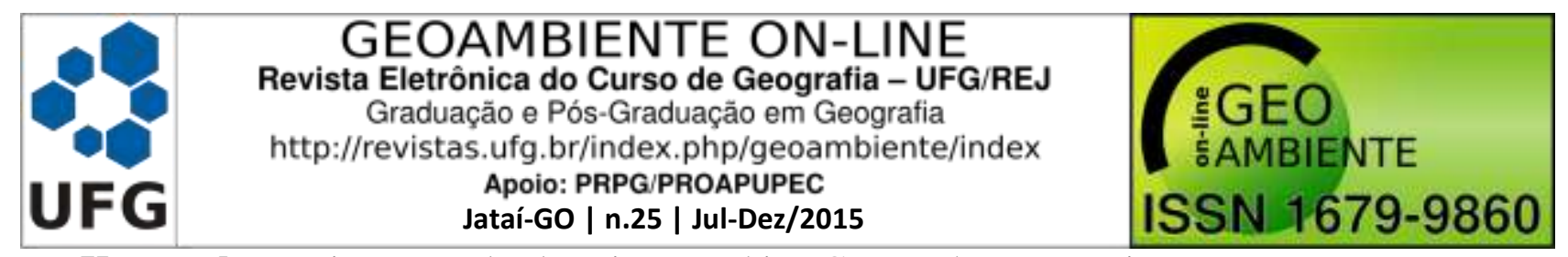

Keywords: Environmental Education Teaching Geography; Perception.

\section{GEOGRAFÍA Y EDUCACIÓN AMBIENTAL: PERCEPCIONES DE MAESTROS EN LA GEOGRAFÍA DE USO COMO HERRAMIENTA PARA LA EDUCACIÓN AMBIENTAL EN BIRIGUI-SP}

Resumem: Disciplina Geografía se aborda varias veces en el PCN (Parámetros Curriculares Nacionales) como elemento central de la educación ambiental, ya que sus conceptos y enfoque directamente relacionados con el medio ambiente. En este contexto, el presente artículo tiene como objetivo aumentar la conciencia de los profesores de Geografía sobre la aplicabilidad de los conceptos de Geografía en las clases de educación ambiental a través de un cuestionario respondido por 20 profesores seleccionados al azar y voluntaria en las escuelas estatales en Birigui-SP. Los datos revelaron que a pesar del trabajo de educación ambiental realizado por el $100 \%$ de los encuestados, todavía necesitan ser resueltos con los maestros del estado algunos conceptos fundamentales de la Geografía.

Palabras clave: Educación Ambiental; La Educación de la geografía; Percepción.

\section{INTRODUÇÃO}

Meio ambiente é o "conjunto de condições, leis, influências e interações de ordem física, química e biológica, que permite, abriga e rege a vida em todas as suas formas [...], o meio ambiente é um patrimônio público a ser necessariamente assegurado e protegido, tendo em vista o uso coletivo" (BRASIL, 1981).

Nesta definição estão contidos os elementos físicos (a terra, o ar, a água), o clima, os elementos vivos (as plantas, os animais, os homens) e também os culturais (os hábitos, os costumes, o saber, a história de cada grupo, de cada comunidade).

Sendo assim, o meio ambiente é a interação entre os meios físico, biológico e socioeconômico e engloba a maneira como os elementos naturais são tratados pela sociedade, ou seja, como as atividades humanas interferem com estes elementos, bem como as interações destes elementos entre si, e entre eles e as atividades humanas.

Assim entendido, o meio ambiente não diz respeito apenas ao meio natural, mas também às vilas, cidades, todo o ambiente construído pelo homem (NEVES;TOSTES, 1992, p. 17).

Compreender este conceito é fundamental, pois coloca a sociedade dentro do meio ambiente. Nesta visão, meio ambiente não está colocado como algo isolado ou intacto, mas 


\begin{tabular}{|c|c|c|}
\hline & $\begin{array}{c}\text { GEOAMBIENTE ON-LINE } \\
\text { Revista Eletrônica do Curso de Geografia - UFG/REJ } \\
\text { Graduaçăo e Pós-Graduaçăo em Geografia } \\
\text { http://revistas.ufg.br/index.php/geoambiente/index } \\
\text { Apoio: PRPG/PROAPUPEC } \\
\text { Jataí-GO | n.25 | Jul-Dez/2015 }\end{array}$ & $\begin{array}{l}\text { ¿GEO } \\
\text { 亡AMBIENTE } \\
\text { ISSN } 1679-9860\end{array}$ \\
\hline
\end{tabular}

em constante interação com o homem. O homem faz parte do meio ambiente, também é meio ambiente, e desenvolver este conceito na sociedade favorece a cidadania, pois cria em cada ser o sentimento de pertence, de se fazer parte, o que na Geografia se traduz no conceito de "lugar". Para Santos (1997), o lugar constitui a dimensão da existência que se manifesta através de um cotidiano compartido entre as mais diversas pessoas. É, portanto, fruto da construção de um elo afetivo entre o sujeito e o ambiente em que vive.

Este trabalho tem como objetivo levantar a percepção de professores a respeito do uso do ensino de geografia para a educação ambiental em Birigui-SP.

\section{Localização da área de estudo}

O município de Birigui está localizado na região noroeste do estado de São Paulo, entre as latitudes $23^{\circ} 03^{\prime} 32^{\prime \prime} \mathrm{S}$ e $23^{\circ} 28^{\prime} 01$ "S, e as longitudes $50^{\circ} 14^{\prime} 29^{\prime \prime} \mathrm{W}$ e $50^{\circ} 27^{\prime} 57^{\prime \prime W}$ (figura 1).

Figura 1 - Localização da área de estudo

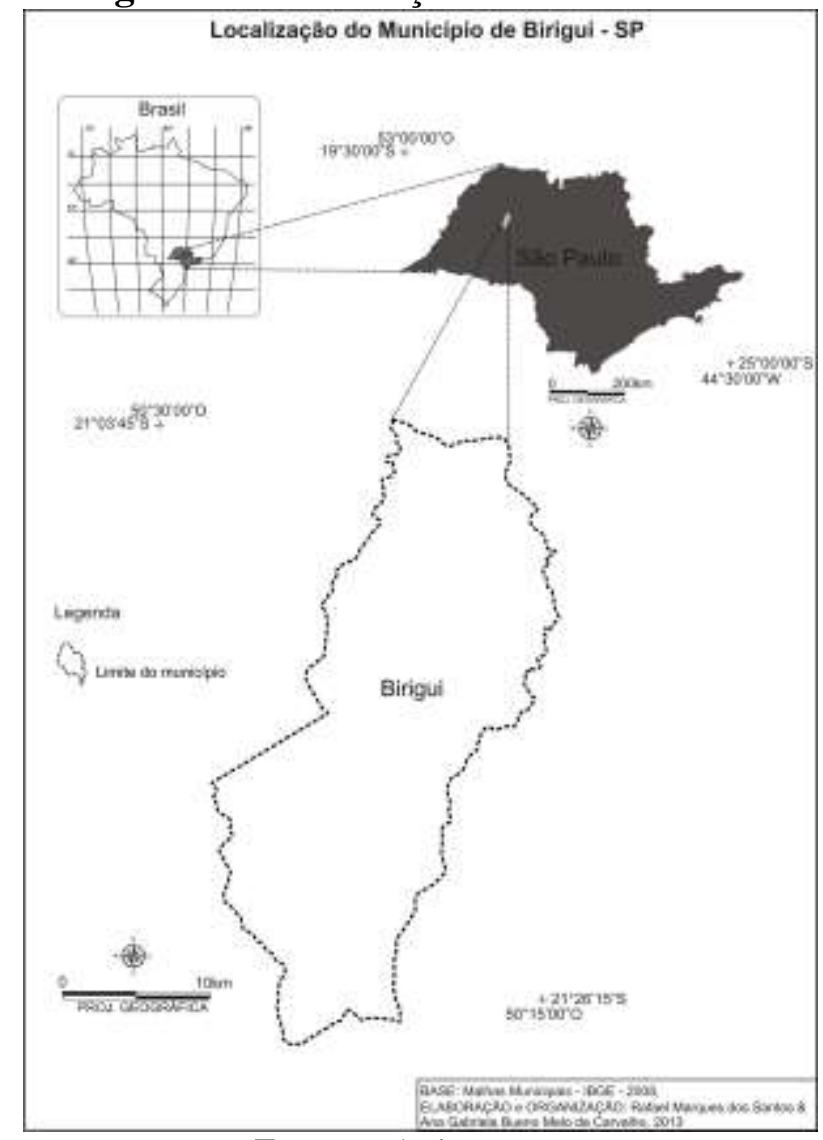

Fonte: Próprios autores 


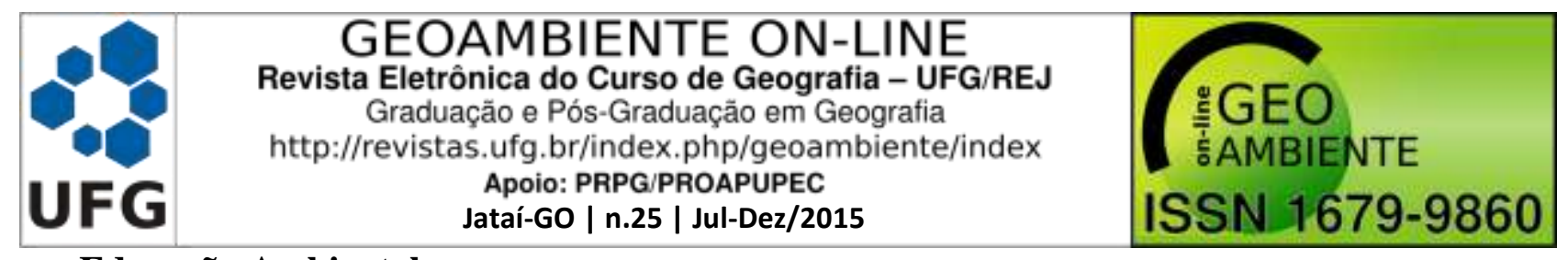

Educação Ambiental

No seu sentido mais amplo, educação significa o meio em que os hábitos, costumes e valores de uma comunidade são transferidos de uma geração para a geração seguinte, e se desenvolve através de situações presenciadas e experiências vividas por cada indivíduo ao longo da sua vida. No sentido técnico, a educação é o processo contínuo de desenvolvimento das faculdades físicas, intelectuais e morais do ser humano visando uma melhor integração do homem a sociedade.

No sentido ambiental, educação ambiental é definida como um instrumento pelo qual “o indivíduo e a coletividade constroem valores sociais, conhecimentos, habilidades, atitudes e competências voltadas para a conservação do meio ambiente” (BRASIL, 1999).

Mas "Por que educar o indivíduo para viver adequadamente no meio ambiente?". Segundo a Constituição Federal, em seu Capitulo VI, artigo 225:

Todos têm direito ao meio ambiente ecologicamente equilibrado, bem de uso comum do povo e essencial à sadia qualidade de vida, impondo-se ao Poder Público e à coletividade o dever de defendê-lo e preservá-lo para as presentes e futuras gerações. (BRASIL, 1988).

Neste contexto, todos têm o direito de receber das gerações passadas um meio ambiente equilibrado, que proporcione uma sadia qualidade de vida, mas mais importante que a garantia é a necessidade da manutenção desta mesma qualidade para as gerações futuras. Portanto, este artigo nos coloca como responsáveis pela qualidade de vida das futuras gerações que necessitarão utilizar de todos os benefícios de um ambiente equilibrado.

No Brasil, esta necessidade foi repassada como fundamento da educação formal. Em 1998, o MEC propõe os temas transversais do PCN. Meio Ambiente uns dos temas transversais, tem como conceito-chave o uso da transversalidade, sendo que esta deve-se situar numa dimensão didática, como meio de articulação entre o saber aprendido na escola e o vivenciado na sociedade (no cotidiano do aluno) (BRASIL, 1998a)

Considera-se que um dos papéis da escola é formar pessoas para o exercício da cidadania. Para isto se faz necessário formar pessoas que compreendam a realidade social dos direitos e responsabilidades em relação à vida individual, coletiva e ambiental. Na questão ambiental:

Assim, a questão ambiental impõe às sociedades a busca de novas formas de pensar e agir, individual e coletivamente, de novos caminhos e modelos de produção de bens, para suprir necessidades humanas, e relações sociais que 


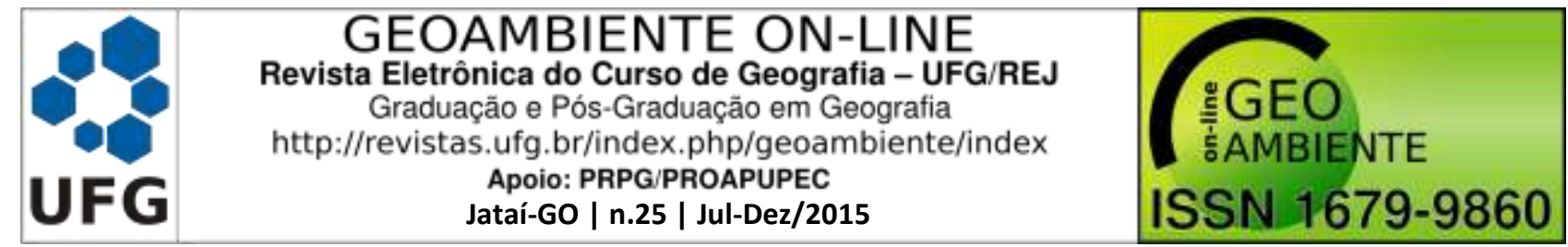

não perpetuem tantas desigualdades e exclusão social, e, ao mesmo tempo, que garantam a sustentabilidade ecológica. Isso implica um novo universo de valores no qual a educação tem um importante papel a desempenhar. (BRASIL, 1998a. p.180)

A Lei $n^{\circ}$ - 9.795/99 aponta princípios e objetivos como referências para a prática pedagógica e para as atividades de formação de professores em Educação Ambiental estabelecendo:

Art. $4^{\circ}$ - São princípios básicos da educação ambiental:

I - o enfoque humanista, holístico, democrático e participativo;

II - a concepção do meio ambiente em sua totalidade, considerando a interdependência entre o meio natural, o socioeconômico e o cultural, sob o enfoque da sustentabilidade;

III - o pluralismo de ideias e concepções pedagógicas, na perspectiva da inter, multi e transdisciplinaridade;

IV - a vinculação entre a ética, a educação, o trabalho e as práticas sociais;

$\mathrm{V}$ - a garantia de continuidade e permanência do processo educativo;

VI - a permanente avaliação crítica do processo educativo;

VII - a abordagem articulada das questões ambientais locais, regionais, nacionais e globais;

VIII - o reconhecimento e o respeito à pluralidade e à diversidade individual e cultural $[\ldots]$

Art. $5^{\circ}$ - São objetivos fundamentais da educação ambiental:

I - o desenvolvimento de uma compreensão integrada do meio ambiente em suas múltiplas e complexas relações, envolvendo aspectos ecológicos, psicológicos, legais, políticos, sociais, econômicos, científicos, culturais e éticos;

II - a garantia de democratização das informações ambientais;

III - o estímulo e o fortalecimento de uma consciência crítica sobre a problemática ambiental e social;

IV - o incentivo à participação individual e coletiva, permanente e responsável, na preservação do equilíbrio do meio ambiente, entendendo-se a defesa da qualidade ambiental como um valor inseparável do exercício da cidadania;

$\mathrm{V}$ - o estímulo à cooperação entre as diversas regiões do País, em níveis micro e macrorregionais, com vistas à construção de uma sociedade ambientalmente equilibrada, fundada nos princípios da liberdade, igualdade, solidariedade, democracia, justiça social, responsabilidade e sustentabilidade;

VI - o fomento e o fortalecimento da integração com a ciência e a tecnologia;

VII - o fortalecimento da cidadania, da autodeterminação dos povos e da solidariedade como fundamentos para o futuro da humanidade. (BRASIL, 1999). 


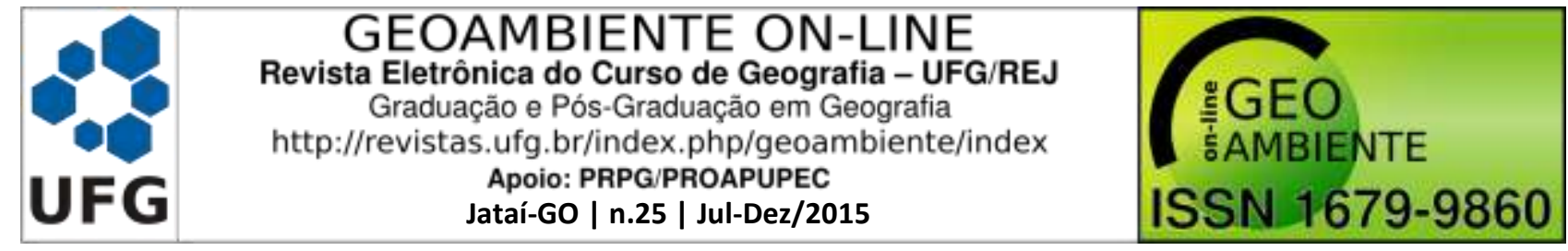

Portanto, as escolas devem trabalhar a educação ambiental para desenvolver atitudes e posturas éticas nos alunos em relação à questão ambiental.

\title{
A Geografia como ferramenta para o ensino de Educação Ambiental
}

A disciplina de Geografia está amplamente ligada a questão ambiental. Segundo o PCN de meio ambiente, a Geografia juntamente com a História e as Ciências Naturais são as tradicionais parceiras para o desenvolvimento dos conteúdos relacionados ao meio ambiente, pela própria natureza dos seus objetos de estudo. (BRASIL, 1998a, p. 194).

\begin{abstract}
A Geografia tem por objetivo estudar as relações entre o processo histórico na formação das sociedades humanas e o funcionamento da natureza por meio da leitura do lugar, do território, a partir de sua paisagem. Na busca dessa abordagem relacional, trabalha com diferentes noções espaciais e temporais, bem como com os fenômenos sociais, culturais e naturais característicos de cada paisagem, para permitir uma compreensão processual e dinâmica de sua constituição, para identificar e relacionar aquilo que na paisagem representa as heranças das sucessivas relações no tempo entre a sociedade e a natureza em sua interação (BRASIL, 1998b, p. 26).
\end{abstract}

Ao se retratar a questão ambiental na escola, se faz necessário o uso da interdisciplinaridade. Meio ambiente não está relacionado somente a parques, árvores ou ao verde. Como retratado anteriormente, a noção de meio ambiente está relacionado à qualidade de vida do homem, e por isto mesmo não deve ser estudado apenas na ótica do meio ambiente natural. A análise de problemas ambientais envolve questões políticas, históricas, econômicas, ecológicas, geográficas, enfim, envolve processos variados, portanto, não seria possível compreendê-los e explicá-los pelo olhar de uma única ciência (BRASIL, 1998b, p. 46).

"[...] Como o objeto de estudo da Geografia, no entanto, refere-se às interações entre a sociedade e a natureza, um grande leque de temáticas de meio ambiente está necessariamente dentro do seu estudo [...]" (BRASIL, 1998b, p. 46), pois, ao abordar as questões sociais e temporais no mundo, obrigatoriamente a Geografia aborda o uso dos recursos naturais. A Geografia relaciona o universo, sociedade e natureza de modo interligado, fazendo o aluno compreender a relação intrínseca existente entre eles e o condicionamento que um exerce sobre o outro:

Além disso, o comportamento de certos fenômenos da natureza está condicionado por múltiplas variáveis, o que dificulta o conhecimento acerca do funcionamento dos diversos ambientes. Dois locais diferentes, por exemplo, com mesmo tipo de solo e com mesmo clima, podem apresentar 


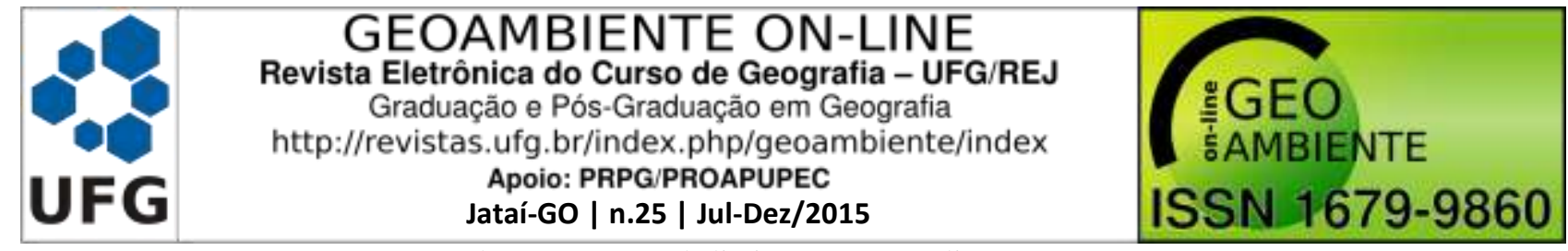

cobertura vegetal distinta, e as explicações que servem para um não servem para o outro.

Compreendê-los implica a aprendizagem de conteúdos de várias áreas, abordados sob diferentes prismas. A aprendizagem, por exemplo, das relações alimentares, seja em Ciências Naturais, em História, em Geografia ou outras áreas, deve incluir os vínculos entre elas e os fluxos da água, do oxigênio e do carbono, a geração do lixo, o uso de insumos agrícolas artificiais, o aproveitamento, o desperdício, o tratamento e a distribuição da água etc.

Dentre as movimentações das substâncias na natureza, uma das mais importantes do ponto de vista ambiental é a da água. (BRASIL, 1998a, p. 208)

Portanto, "[...] a proposta de Geografia para estudo das questões ambientais favorece uma visão clara dos problemas de ordem local, regional e global, ajudando a sua compreensão e explicação, fornecendo elementos para a tomada de decisões e permitindo intervenções necessárias [...]" (BRASIL, 1998b, p. 46).

A ampliação da escala espacial permite compreender melhor processos importantes para a dinâmica ambiental, como a distribuição das espécies no planeta. Aqui, a área de Geografia pode contribuir de forma decisiva, apontando as relações entre os elementos físicos do ambiente e sua influência na distribuição espacial dos seres vivos. (BRASIL, 1998a, p. 207)

\section{METODOLOGIA}

A metodologia do trabalho consistiu em levantamentos bibliográficos e aplicação de questionário a professores de Geografia do ensino fundamental e médio das escolas estaduais da cidade de Birigui-SP a respeito do uso da Geografia como ferramenta para a educação ambiental.

Foram entrevistados 20 professores que lecionam aulas de Geografia para o Ensino Fundamental e Médio das escolas estaduais de Birigui. Esta amostragem foi feita aleatoriamente, de maneira voluntária e os professores pesquisados se mantiveram sem identificação.

\section{RESULTADOS E DISCUSSÕES}

Os primeiros questionamentos foram feitos com o intuito de se levantar o perfil do entrevistado: 50\% eram mulheres e 50\% eram homens, a maioria tinha entre 26 e 35 anos e possuíam o ensino superior completo. A área de formação de quase a totalidade dos entrevistados era em Geografia Plena, porém alguns ainda possuíam outras formações (em História, Letras e Pedagogia), em apenas um único caso o entrevistado possuía apenas a 


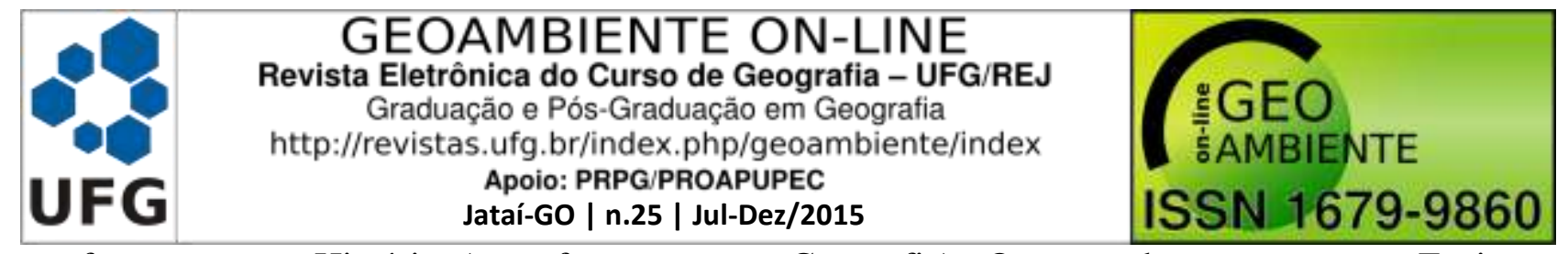

formação em História (sem formação em Geografia). Quase todos atuavam no Ensino Fundamental e Médio simultaneamente (figura 2).

Figura 2 - Perfil dos Entrevistados

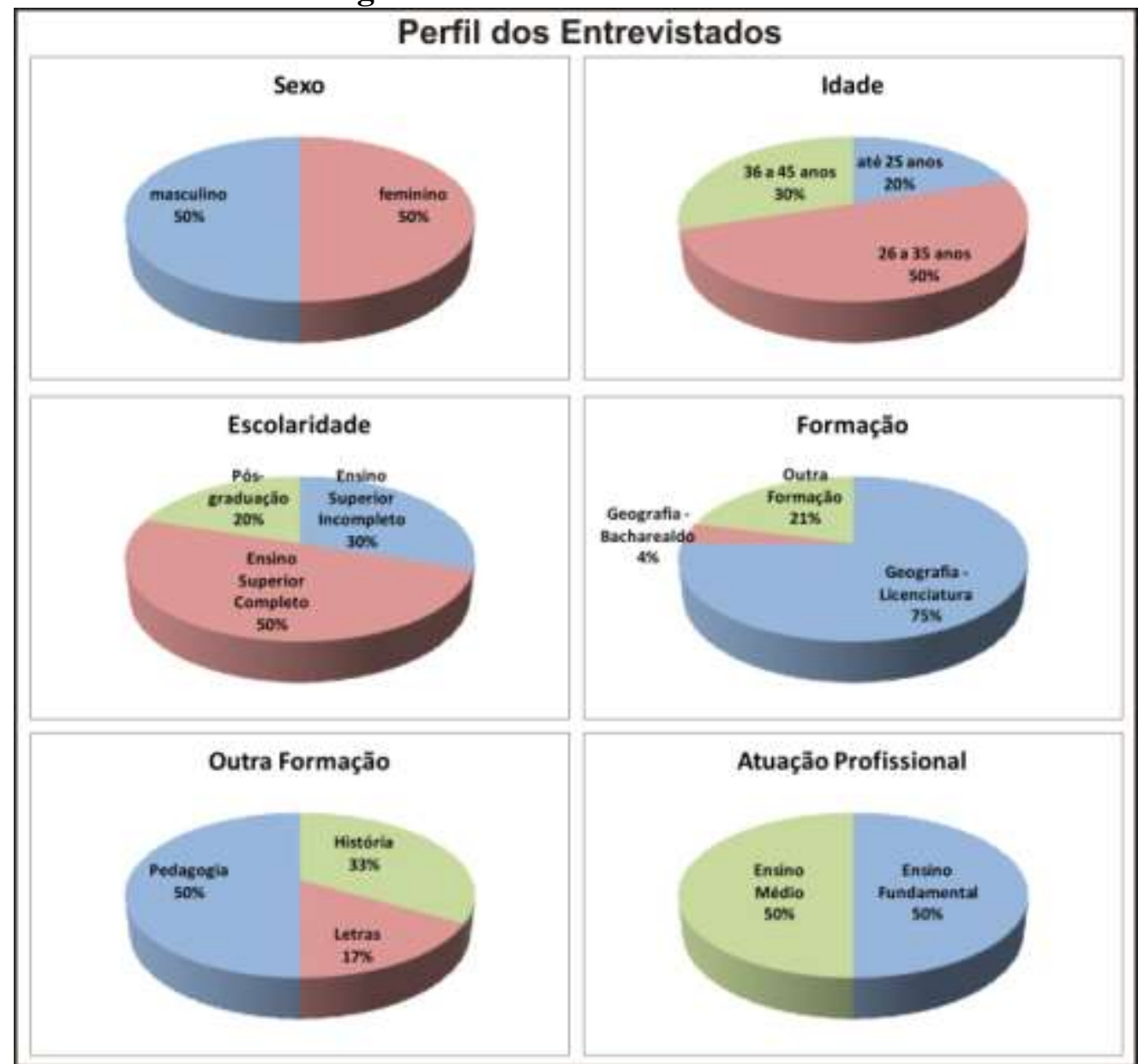

Fonte: Próprios autores

Quando se questionou os entrevistados sobre o trabalho com educação ambiental, todos responderam que sim, que trabalham com o tema em sala de aula. Ao se perguntar a maneira como o tema era trabalhado com os alunos, 16 disseram que fazem uso de aulas teóricas, 16 utiliza a pesquisa em livros e internet e apenas 6 fazem uso de saídas de campo, porém disseram que só as realizam quando há condições para as mesmas, revelando o interesse de uma maior atuação deste método de ensino (figura 3). Sobre o uso dos parâmetros curriculares nacionais de meio ambiente $(\mathrm{PCN})$, metade dos professores revelaram não utilizá-lo com base em suas aulas sobre educação ambiental o que revela um possível desconhecimento do instrumento, já que os temas trabalhados no PCN estão totalmente de encontro com a Geografia (figura 4).

Figura 3 - Abordagem do tema 


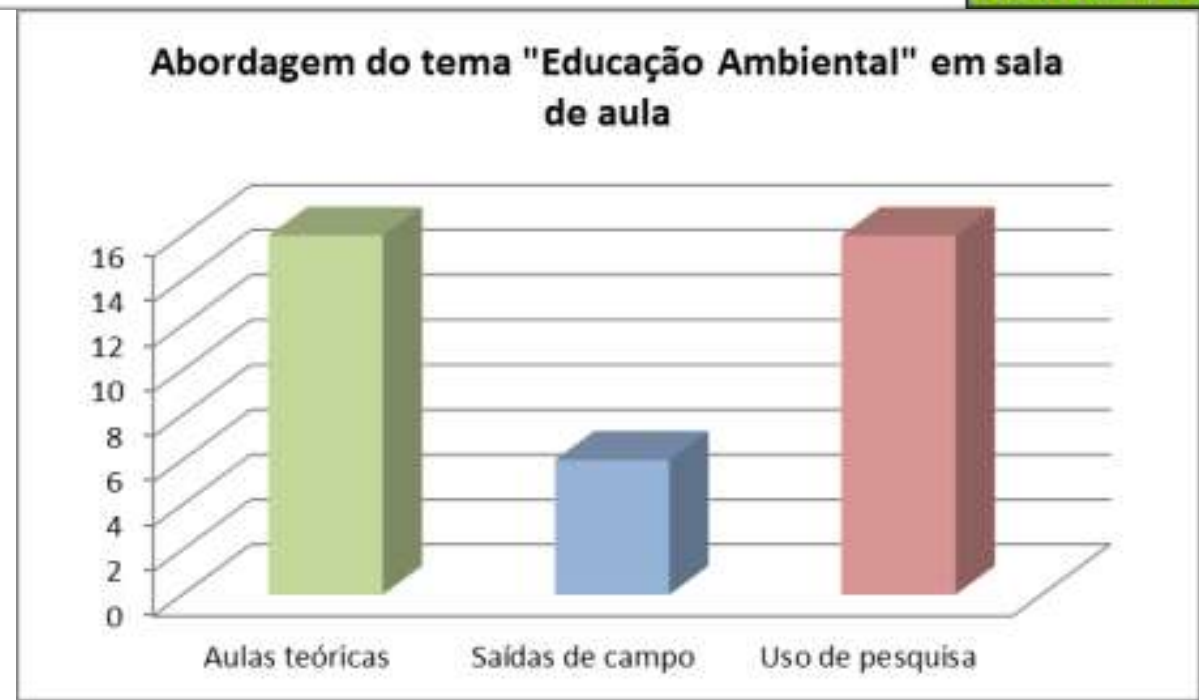

Fonte: próprios autores

Figura 4 - Uso do PCN

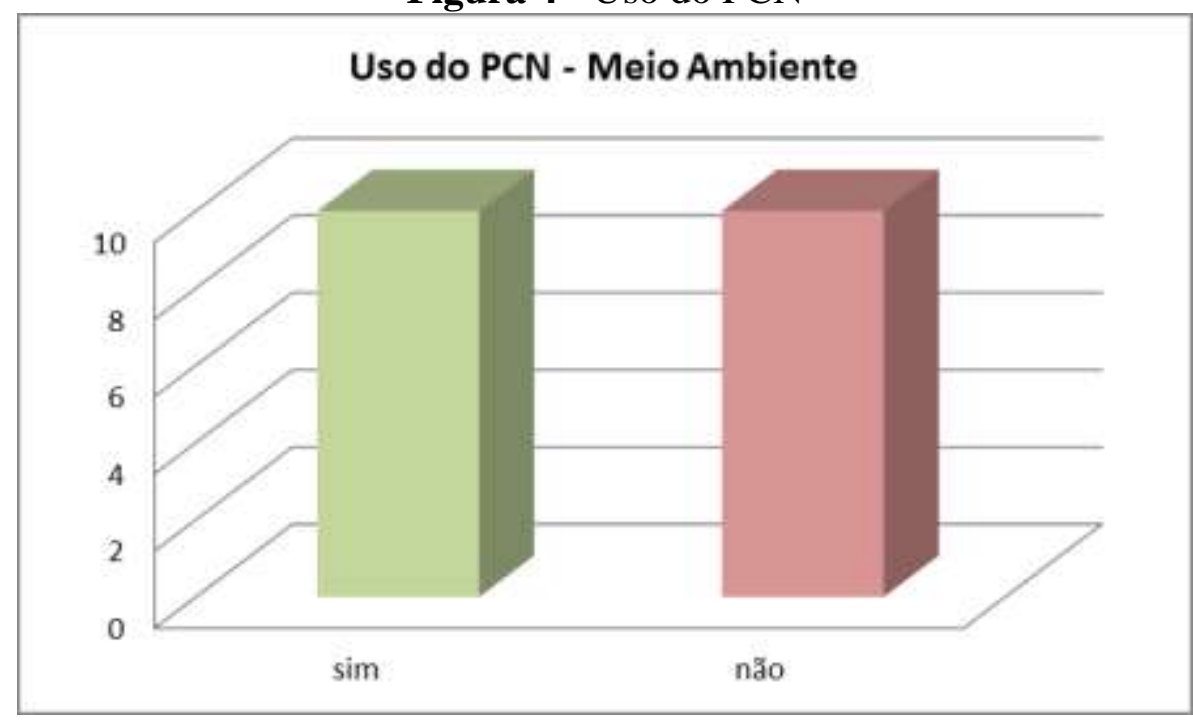

Fonte: próprios autores

Questionou-se também sobre o uso dos seguintes conceitos da Geografia nas aulas de educação ambiental: 16 professores dizem utilizar o conceito de paisagem, 14 o de lugar, 12 o de território e 18 o de região. Outros conceitos foram mencionados pelos entrevistados: urbanização, desenvolvimento sustentável, espaço geográfico e reciclagem (figura 5 e 6).

Monteiro (2001) define paisagem no nível de resolução para a análise da "paisagem" e sob o enfoque da organização sistêmica, como um sistema aberto, uma unidade de análise geográfica global, "geo sistema". Para o autor, trata-se de uma entidade espacial delimitada segundo um nível de resolução do geógrafo (pesquisador) a partir dos objetivos centrais da análise, de qualquer modo sempre resultante da integração dinâmica, portanto instável, dos elementos de suporte e cobertura (físicos, biológicos e antrópicos), expressa em partes delimitáveis infinitamente, mas individualizadas através das relações entre elas, que 


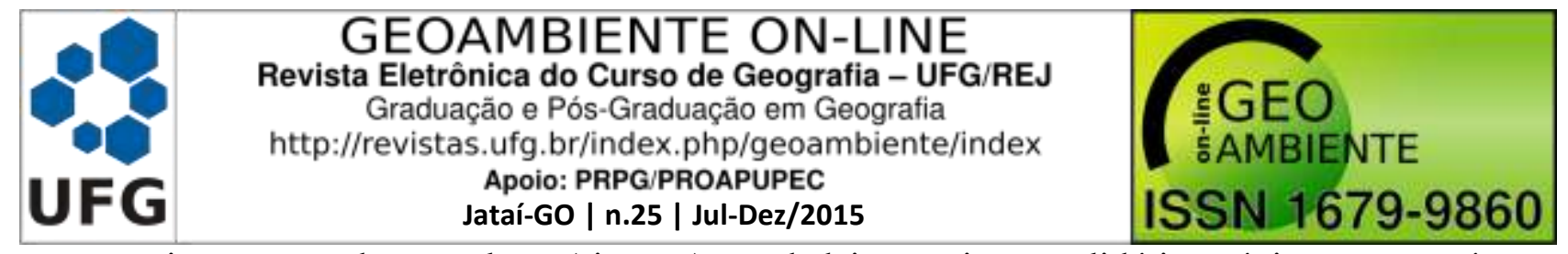

organizam um todo complexo (sistema), verdadeiro conjunto solidário e único em perpétua evolução.

Figura 5 - Abordagem do tema

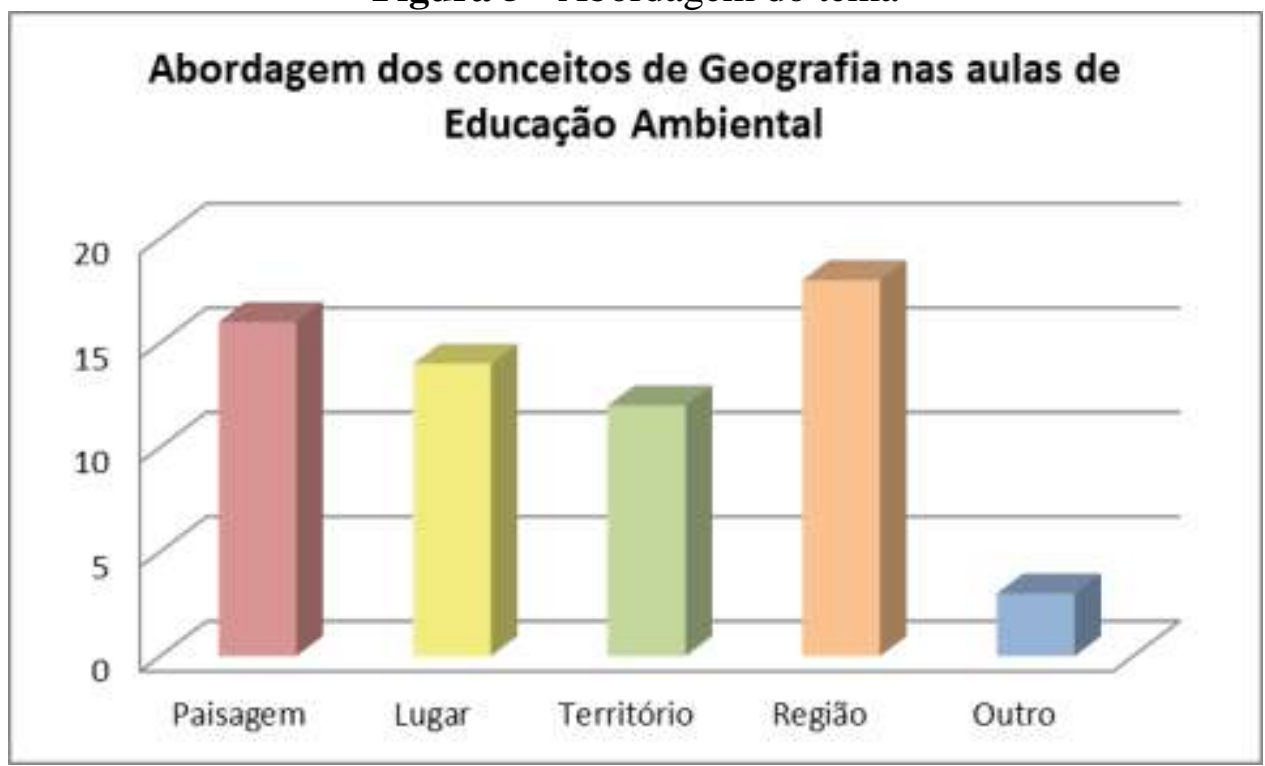

Fonte: Próprios autores

Figura 6 - Uso do PCN

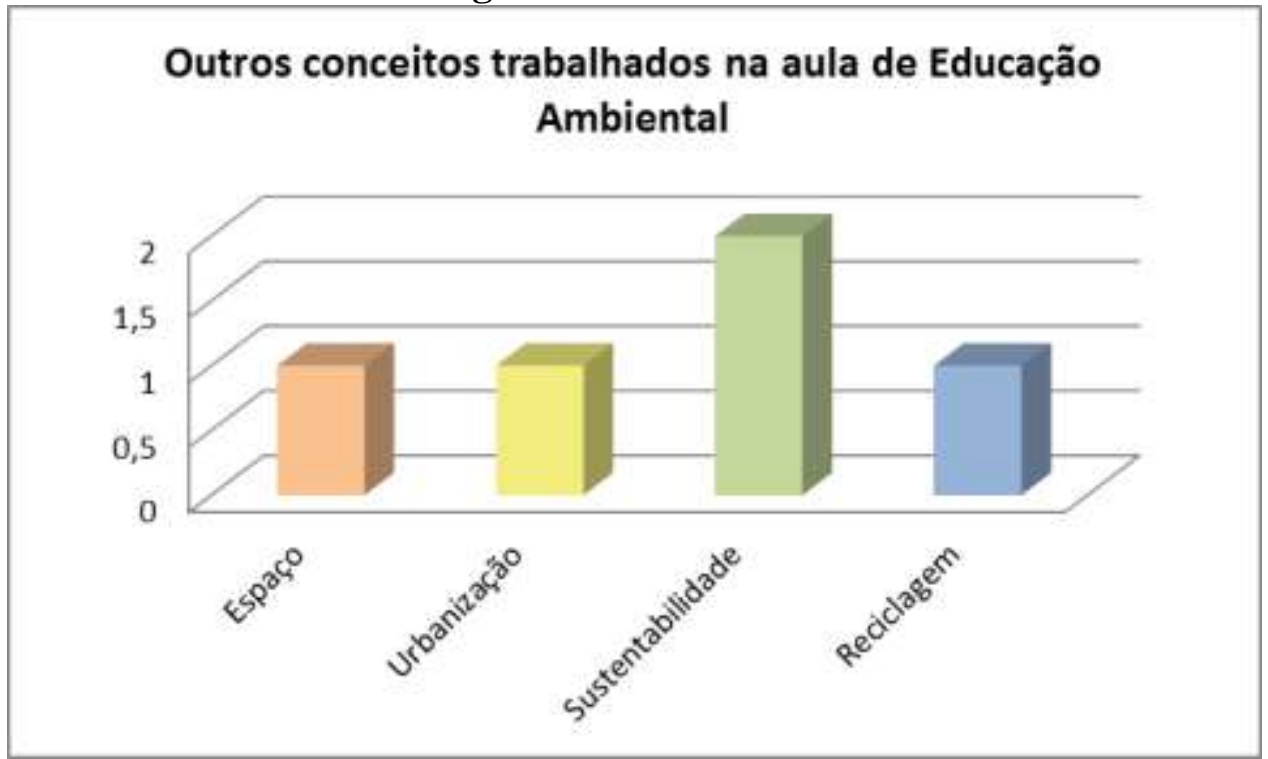

Fonte: próprios autores

Em sala de aula, o professor pode abordar este conceito em quase todas as situações, visto que a paisagem pode ser trabalhada de forma direta (em saídas de campo, por exemplo) ou indireta (com o uso de fotografias, filmes e outros recursos). A leitura da paisagem transfere ao aluno sensações, sentimentos individuais que não seriam alcançados através de aulas abstratas. Para educação ambiental este conceito é muito importantes pois faz o aluno 


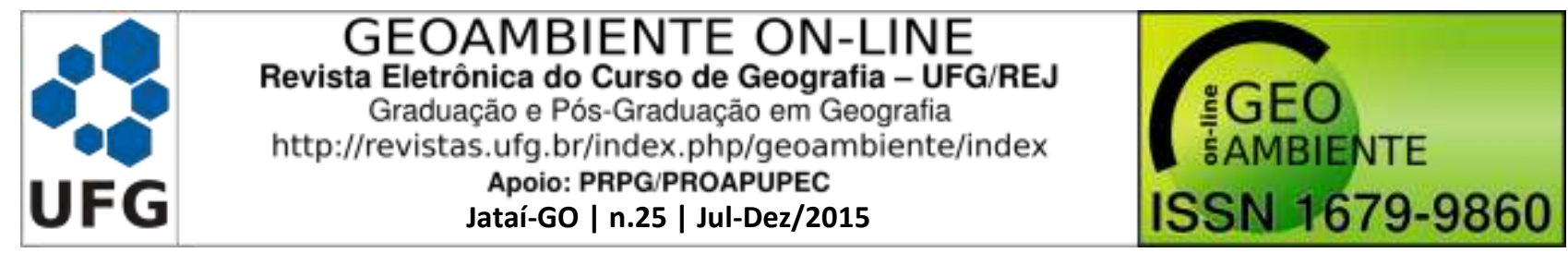

visualizar o problema e a solução ao mesmo tempo, e optar por um comportamento mais adequado.

Quanto ao método de análise da paisagem pode-se adotar três possibilidades de encaminhamento: a descritiva, a sistêmica e a perceptiva:

A análise da paisagem descritiva tem como base a descrição; e, para a apreensão da paisagem, seriam necessárias a enumeração dos elementos presentes e a discussão das formas. Assim, a análise estaria restrita aos aspectos visíveis do real e, essencialmente, à morfologia da paisagem.

A análise da paisagem sistêmica sugere o estudo da combinação dos elementos físicos, biológicos e sociais, um conjunto geográfico indissociável, uma interface entre o natural e o social, sendo, portanto, uma análise em várias dimensões. O relacionamento e a análise que separam os elementos que constituem as diferentes características espaciais, psicológicas, econômicas, ecológicas etc. não permitem, no entanto, dominar o conjunto. A complexidade da paisagem está relacionada a três dimensões de análise: a da morfologia (forma), a da estrutura e a da funcionalidade, não podendo ela ser reduzida somente à descrição das partes que compõem a paisagem, mas procurando-se entender como estas três dimensões se relacionam e geram a paisagem ante o olhar humano.

A análise da paisagem perceptiva é concebida como uma marca e uma matriz. Como marca, a paisagem deve ser descrita, inicialmente, como um inventário. Como matriz, a paisagem deve ser analisada como um produto da realidade concreta, mas, ao mesmo tempo, deve ser concebida como o produto da imaginação, a representação dessa realidade, ou seja, pelas imagens que são expressas pelo indivíduo e o coletivo. (VERDUM; PUNTEL, 2010, p. 81-82).

Para Raffestin (1993, p.50) "o território [...] é um espaço onde se projetou um trabalho, seja energia e informação, e que, por consequência, revela relações marcadas pelo poder. O espaço é a 'prisão original', o território é a prisão que os homens constroem para si". Portanto, qualquer espaço definido e delimitado por e a partir de relações de poder, e não somente relacionado a fronteiras, se caracteriza como território. Esta definição é caracterizada pela ideia de posse, domínio e poder, correspondendo ao espaço geográfico socializado, apropriado para os seus habitantes, independentemente da extensão territorial.

Em sala de aula pode-se trabalhar o conceito com educação ambiental ao abordar a ideia de acordos e conflitos territoriais relacionados ao meio ambiente, como por exemplo a produção de lixo entre países pobres e ricos, a disponibilidade de recursos naturais entre os países e a consequente influência do mesmo na vida socioeconômica de seus habitantes. bem como utilizar esta mesma ótica em uma escala mais local e/ou regional.

O conceito de região está relacionado ao agrupamento de áreas semelhantes de acordo com um propósito pré-definido (social, econômico ou natural). Para Corrêa (1986, p. 186): 


\begin{tabular}{|c|c|c|}
\hline & $\begin{array}{c}\text { GEOAMBIENTE ON-LINE } \\
\text { Revista Eletrônica do Curso de Geografia - UFG/REJ } \\
\text { Graduação e Pós-Graduaçäo em Geografia } \\
\text { http://revistas.ufg.br/index.php/geoambiente/index } \\
\text { Apoio: PRPG/PROAPUPEC } \\
\text { Jataí-GO | n.25 | Jul-Dez/2015 }\end{array}$ & $\begin{array}{l}\text { ¿GEO } \\
\text { 亡.AMBIENTE } \\
\text { ISSN } 1679-9860\end{array}$ \\
\hline
\end{tabular}

Considera a região a partir de propósitos específicos, não tendo a priori, como no caso da região natural e da região-paisagem, uma única base empírica. É possível identificar regiões climáticas, regiões industriais, regiões nodais, ou seja, tantos tipos de regiões quantos forem os propósitos do pesquisador. A região natural e a região paisagem passam a ser apenas uma das múltiplas possibilidades de se recortar o espaço terrestre. A região constitui-se para os geógrafos lógico-positivistas em uma criação intelectual, criada a partir de seus propósitos específicos.

Na ótica da educação ambiental, este conceito pode ser trabalhado em sala de aula através do agrupamento e compreensão de áreas naturalmente semelhantes. Pode-se também abordar as influências destas similaridades na formação da sociedade, visto que a Geografia acredita no condicionamento do homem pela natureza e a influência do homem na natureza.

Lugar é uma porção ou parte do espaço onde vivemos nosso dia-a-dia, em interação com uma paisagem, ou seja, numa relação de vínculo e de convívio. O estudo do lugar como possibilidade de aprender geografia considera o cotidiano da vida dos alunos e o contexto escolar como fundamentos. Neste sentido, lugar e cotidiano são abordados no contexto escolar como oportunidade de desenvolver habilidades e competências que contribuem para a formação cidadã e para a construção de conceitos constitutivos da especificidade do conhecimento geográfico e para o estabelecimento das bases da aprendizagem da geografia na escola básica (CALLAI, 2010). Ainda sobre o conceito de lugar, questionaram-se os professores sobre a utilização da realidade local (cidade, bairro, rua) onde a escola está inserida no trabalho com meio ambiente, sendo que 12 professores responderam que fazem uso do lugar nas aulas de educação ambiental (ver figura 7).

Alguns professores deixaram os pontos abordados nas aulas relacionados ao lugar onde vivem:

Trabalho temas relacionados a nossa cidade como: coleta seletiva, reciclagem, esgoto e lixo, bem como o assoreamento de nossos rios.

Eu trabalho com o projeto ambiente sustentável e com os temas relacionados ao nosso bairro como geologia, fragilidade, produção de lixo (industrial, doméstico e hospitalar) e planejamento urbano. Parto pelos conceitos da paisagem que os cercam, pois é a que estão habituados, como as ruas, os campos e as calçadas.

Utilizo todo o conteúdo de escala local elou regional, como por exemplo, a poluição do córrego Biriguizinho que corta a cidade.

Abordo o tema poluição em rios, utilizando como exemplo os córregos das imediações. Trabalho também como coleta de lixo e a importância da arborização, além de outras propostas curriculares. Trabalho com os alunos observando os arredores da escola.

(respostas obtidas no questionário aplicado pelo autor) 


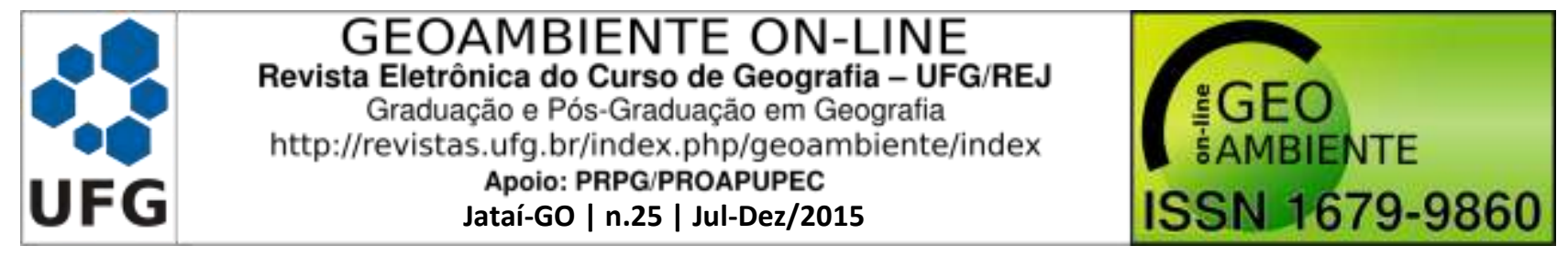

Figura 7 - Compreensão do lugar

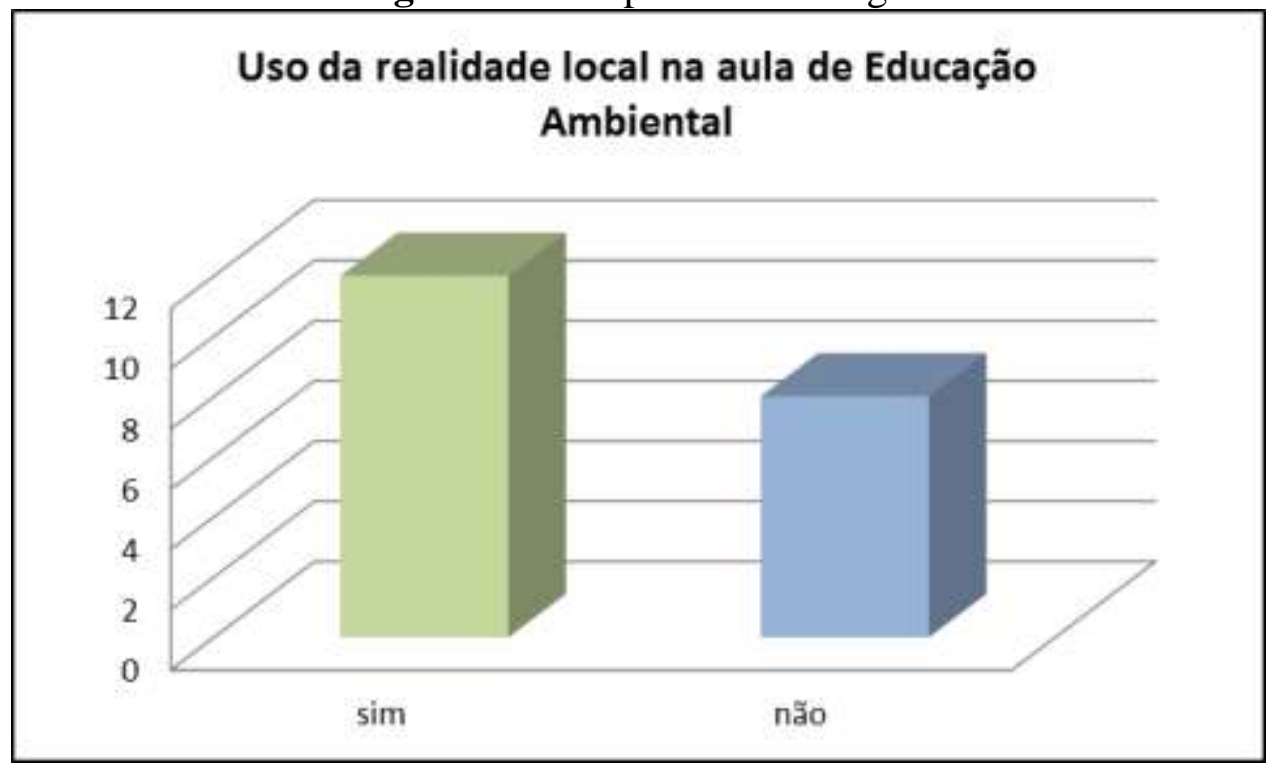

Fonte: Próprios autores

O resultado deste questionamento revela que poucos professores ainda trabalham com a educação ambiental de maneira mais completa, partindo do local. É importante que o aluno desenvolva a noção de pertence, que ele entenda que faz parte do meio ambiente, e que precisa de um meio ambiente equilibrado para viver bem e promover a garantia da existência de gerações futuras. O aluno precisa compreender que preservar, ou seja, manter intocável, não pode ser aplicável para todas as situações, visto que precisamos do bem natural para a manutenção da vida, e que por isso o fundamental é fazer o mesmo compreender que devemos conservar os recursos naturais. E bem mais que uma cultura de economia (não que esta não seja importante), devemos estimular uma cultura de conhecimento. Quando conhecemos a origem, o uso, o tratamento e a deposição de um recurso natural, somos capazes de propor mudanças e fiscalizar ações.

\section{CONSIDERAÇÕES FINAIS}

A Geografia trabalha com a compreensão do meio ambiente, na sua escala local, regional e global. Analisa todos os seus componentes, naturais, sociais e econômicos, e por este motivo é uma ferramenta importantíssima para a educação ambiental, visto que a mesma trabalha conceitos que podem ser utilizados amplamente no trabalho e apreensão do conhecimento pelos estudantes.

Os resultados revelaram uma preocupação por parte de $100 \%$ dos entrevistados com o tema "educação ambiental". No entanto, o questionário apontou que muitos professores ainda 


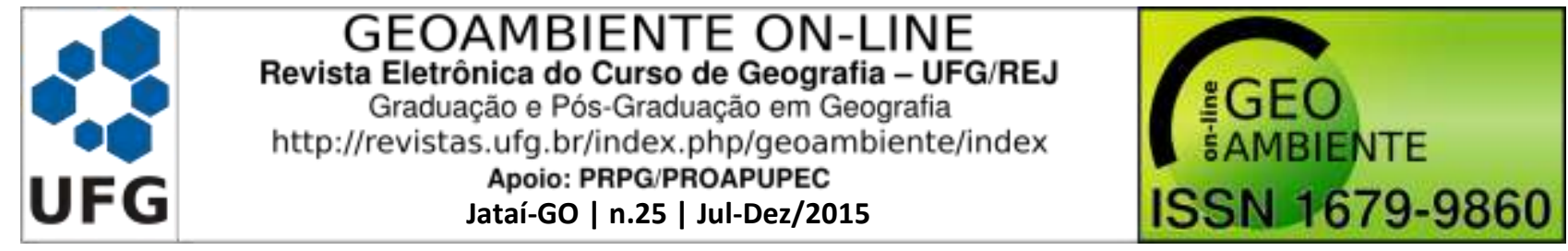

não se sentem familiarizados e seguros com o uso dos conceitos da Geografia e sua aplicabilidade na educação ambiental.

Para que as aulas de educação ambiental sejam realizadas pelos professores com o máximo de aproveitamento por parte dos alunos se faz necessário um aprofundamento dos conceitos e fundamentos da Geografia como ciência. Sugere-se cursos de aprimoramento no saber geográfico, que podem ser oferecidos pelas escolas ou pela diretoria de ensino a seus professores.

A cidade de Birigui conta com uma faculdade de Geografia. Podem-se realizar parcerias entre docentes (de nível superior, médio e fundamental) para a discussão e compreensão dos conceitos, bem como para o desenvolvimento e partilha de técnicas e métodos de aula.

É importante reconhecer as características da organização do espaço, as tecnologias associadas a essa organização e suas consequências ambientais. Por meio da Geografia, por exemplo, os alunos podem compreender melhor como são estruturadas as pequenas propriedades rurais (com agricultura de subsistência) e os tipos e amplitudes mais comuns de poluição nessas áreas. Analogamente, é possível pesquisar como se dá essa organização nos grandes latifúndios. Tanto em Geografia quanto em História, é possível, além de explorar os aspectos técnicos, buscar que o aluno entenda quais as relações histórico-sociais em que se dá a intervenção humana na natureza, aquelas que garantem, por exemplo, a manutenção dos latifúndios e como isso ocorre no caso das pastagens e da monocultura. Associado a isso, é interessante que os alunos conheçam tanto as implicações ambientais físicas quanto as relativas à qualidade de vida. (BRASIL, 1998a, p. 213).

\section{REFERÊNCIAS}

BRASIL. Lei 6.938. Dispõe sobre a Política Nacional do Meio Ambiente, seus fins e mecanismos de formulação e aplicação, e dá outras providências. Brasília, DF, 31 ago 1981. Disponível em: http://www.planalto.gov.br/ccivil_03/leis/16938.htm. Acesso em: 25 ago 2013.

Constituição da República Federativa do Brasil de 1988. Brasília, DF, 05 out 1988. Disponível em: http://www.planalto.gov.br/ccivil_03/constituicao/constituicaocompilado.htm. Acesso em: 25 ago 2013.

Secretaria de Educação Fundamental. Parâmetros curriculares nacionais: terceiro e quarto ciclos - apresentação dos temas transversais. Brasília : MEC/SEF, 1998a. 436 p. Disponível em: http://portal.mec.gov.br/seb/arquivos/pdf/ttransversais.pdf. Acesso em: 07 set 


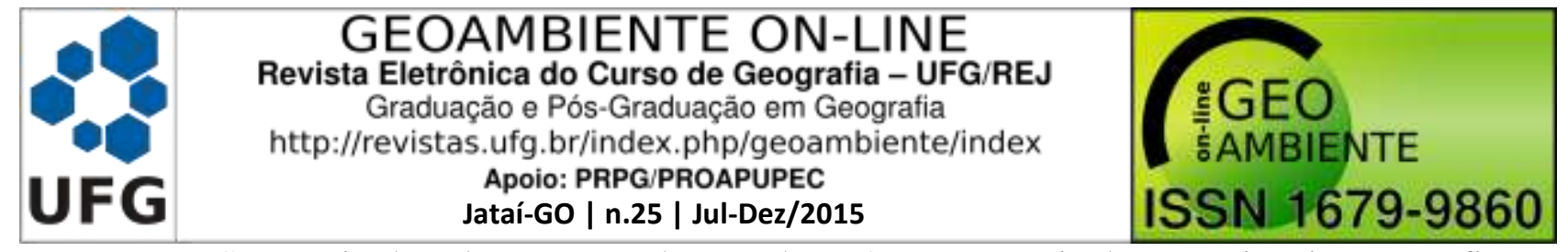

Secretaria de Educação Fundamental. Parâmetros curriculares nacionais: geografia terceiro e quarto ciclo do ensino fundamental. Brasília : MEC/SEF, 1998b. 156 p. Disponível em: http://portal.mec.gov.br/seb/arquivos/pdf/geografia.pdf. Acesso em: 07 set 2013.

Lei 9.795. Dispõe sobre a educação ambiental, institui a Política Nacional de Educação Ambiental e dá outras providências. Brasília, DF, 27 abr 1999. Disponível em: http://www.planalto.gov.br/ccivil_03/leis/19795.htm. Acesso em: 25 ago 2013.

CALLAI, H.C. Escola, cotidiano e lugar. In.: BUITONI, M.M.S.(coord). Geografia: ensino fundamental. Brasília: Ministério da Educação. 252 p. 2010.

CORRÊA, R. L. Região e organização espacial. São Paulo: Ática. 96 p. 1986.

MONTEIRO, C. A. Geossistema: a história de uma procura. São Paulo. Contexto. 127 p. 2001.

NEVES, E; TOSTES, A. Meio ambiente: a lei em suas mãos. Petrópolis: Vozes, 1992. 87 p.

RAFFESTIN, C. Por uma Geografia do Poder. São Paulo: Ática, 242 p. 1993.

RAFFESTIN, C. Écogenèse territoriale et territorialité. In: F. Auriac et R. Brunet (Dir.). Espaces jeux et enjeux. Paris : Fayard, Fondation Diderot. p. 173-185. 1986.

SANTOS, M. Espaço e método. 4. ed. São Paulo: Nobel, 120 p. 1997.

VERDUM, R.; PUNTEL, G.A. Espaço geográfico e paisagem. In.: BUITONI, M.M.S. (coord). Geografia: ensino fundamental. Brasília: Ministério da Educação. 252 p. 2010. 